\title{
VEINTE AÑOS DE HISTORIA DE AMÉRICA EN LA REVISTA TROCADERO
}

\author{
Gema Feijoo Carrillo \\ Manuel Jesús Gomar Jarana \\ Universidad de CÁdiz
}

El presente trabajo pretende realizar un repaso a través de todos los artículos publicados por el Área de Historia de América dentro de la Revista Trocadero de la Universidad de Cádiz.

La revista Trocadero nació en el año 1989 y desde entonces ha publicado, con una periodicidad anual, un total de veinte números, el último de ellos, el número 20, en el año 2008. Esta publicación de divulgación científica, dirigida actualmente por la Dra. Gloria Espigado Tocino, Profesora Titular de Historia Contemporánea de la Universidad de Cádiz, es fruto del trabajo del Departamento de Historia Moderna, Contemporánea, de América y del Arte de la Universidad de Cádiz, dirigido por el Profesor Dr. Alberto Ramos Santana. En este artículo vamos a analizar los títulos referidos únicamente al Área de Historia de América.

Hay que aclarar que de los 20 números de Trocadero editados hasta la fecha por el Servicio de Publicaciones de la Universidad de Cádiz (UCA), sólo contienen artículos referidos a Historia de América los números 4 (1992), 6-7 (1994-1995), 8-9 (1996-1997), 10-11 (1998-1999), 14-15 (2002-2003), 16 (2004), 17 (2005), 18 (2006), 19 (2007) у 20 (2008) у sobre éstos vamos a trabajar. Mientras que los números 1 (1989), 2 (1990), 3 (1991), 5 (1993) y 12-13 (2000-2001) no incluyen ningún título acerca de nuestra materia de estudio.

Tenemos un total de setenta y dos artículos repartidos entre sesenta y cinco autores. Reseñas de autoría conjunta son cinco: "Dictadura militar argentina (1976-1983): Procesos e investigaciones judiciales”, n. ${ }^{\circ}$ 10-11 (1998-1999), pp. 253-272, obra de Carmen Ponce Alonso, M. ${ }^{a}$ Carmen Sánchez Jurado y M. ${ }^{a}$ Mar Sánchez Riobó (Universidad de Cádiz); “Guía y vademécum del conquistador”, n. 16 (2004), de M. Cuesta 
Domingo y F. López-Ríos (Universidad Complutense de Madrid); “El Género, una categoría de análisis crítico que nos cuenta otra Historia”, n. ${ }^{\circ} 17$ (2005), a cargo de Blanca Elisa Cabral y de Edda O Samudio A. (Universidad de los Andes, Mérida, Venezuela); “Cádiz: Plataforma de emigración a Indias. 1750-1760”, n. ${ }^{\circ}$ (1992), pp. 85-110, obra del Grupo Indiano"; e "Historia Oral y trabajo de campo sobre emigrantes andaluces residentes en Argentina”, n. ${ }^{\circ}$ 6-7 (1994-1995), del Grupo Intrahistoria ${ }^{2}$. El resto de las recensiones son obra de un solo autor.

En cuanto a la procedencia de los investigadores que han participado en el apartado de Historia de América de nuestra revista, decir que es muy variada. Así pues, tenemos una gran mayoría de autores procedentes, como es lógico, de la Universidad de Cádiz, tales como: María del Mar Barrientos Márquez, Marisol Dorao, David Fernández Fernández, Fernando L. García de Sola Márquez, María Dolores Pérez Murillo, Juan Carlos Romero López, Juan Aquilino Cascón Becerra, María Dolores Fuentes Bajo, Alberto J. Gullón Abao, Raúl Hernández Asensio, María José Portela Miguélez, etcétera.

También contamos con la participación de investigadores de otras universidades españolas, como. María Magdalena Guerrero Cano, procedente de la Universidad de Granada; José Luis de Rojas, M. Cuesta Domingo y F. López-Ríos, de la Universidad Complutense de Madrid; y Luhé Palma Chazarra, del Instituto Andaluz de Criminología (Universidad de Sevilla). Asimismo, tenemos a especialistas como Beatriz Vitar Muksdi, del Consejo Superior de Investigaciones Científicas (CSIC) de Madrid.

Representantes de universidades y de instituciones educativas latinoamericanas tampoco faltan entre nuestros autores. Este es el caso, por ejemplo, de Ramón de Armas, procedente del Centro de Estudios Martianos de La Habana (Cuba). De la también cubana Universidad de La Habana procede a su vez Felicia Chateloin Santiesteban.

De Venezuela vienen Elida Aponte Sánchez (Universidad del Zulia); Blanca Elisa Cabral y Edda O Samudio A., de la Universidad de los Andes (Mérida) y Francisco Tiapa, del Instituto Venezolano de Investigaciones Científicas.

De Brasil son originarios: Jaime Lucio Fernandes Ribeiro (Universidad Fluminense, Río de Janeiro) y Leonardo Soares Dos Santos (Universidade Federal Fluminense).

De la República Argentina contamos con gente como: Susana Bianchi, del Instituto de Estudios Histórico-Sociales (IEHS) de la Universidad Nacional del Centro de la Provincia de Buenos Aires (UNCPBA); María Teresa Luiz (Universidad Nacional de la Patagonia “San Juan Bosco”, Sede Ushuaia); Viviana Kluger, de la Universidad de Buenos Aires y Ana T. Fanchín, de la Universidad de San Juan.

De México son Sergio Antonio Corona Páez (Universidad Iberoamericana Torreón) y Jorge Victoria Ojeda (Archivo General del Estado de Yucatán).

Y por último, de la República del Ecuador tenemos a Raúl Hernández Asensio (Universidad Andina Simón Bolívar, Quito).

Las autoras más prolíficas en cuanto a número de artículos publicados en Trocadero son María Magdalena Guerrero Cano (Universidad de Granada) y María Dolores Pérez Murillo (UCA), con un total de cinco reseñas cada una.

Las cinco obras de la Dra. Guerrero Cano son las que siguen a continuación:

- “Creación y desmantelamiento de la iglesia metropolitana de Santo Domingo (1547-1802)”, Trocadero: Revista de historia moderna y contemporánea, ISSN 0214-4212, n. ${ }^{\circ} 4$ (1992), pp. 197-202. 
- “El Saint Domingue que conoció René Dupé”, n. o 6-7 (1994-1995)

- "Un dominicano en el colegio de nobles americanos de Granada. Familia y genealogía de Juan Clemente Martínez Saviñón, n. o 8-9 (1996-1997), pp. 383-400.

- "Expediciones a Santo Domingo. El fracaso de un proyecto de colonización (1860-1862), n. ${ }^{\circ}$ 14-15 (2002-2003), pp.63-92.

- “El contexto antillano y el centro hispano-ultramarino de Cádiz”, n. ${ }^{\circ} 20$ (2008), pp. 113-125.

Seguidamente, procederemos a hacer una breve valoración acerca de uno de los artículos de M. ${ }^{a}$ Magdalena Guerrero Cano. A modo de ejemplo escogeremos el titulado “El Saint Domingue que conoció René Dupé”. La razón de que sólo hagamos observaciones sobre uno de los artículos de esta investigadora obedece a razones de espacio.

Para la realización de este estudio Guerrero Cano ha recurrido a los Archivos Nacionales de París, sección histórica de "Marina y Colonias", donde se recogen datos sobre Saint Domingue (el actual Haití, colonia francesa hasta su independencia en 1804). En estos textos nos encontramos con descripciones de las Antillas o con las cartas de algunos colonos, pero hay que decir que consisten fundamentalmente en documentación protocolaria y burocratizada, como actas notariales, testamentos, escrituras de compra-venta, constitución de sociedades, legislación sobre libertad de comercio...

Este estudio intenta explicar cómo era la sociedad en la isla de Saint Domingue, en los años que siguieron al estallido de la Revolución Francesa (1789). En este territorio se emplearon como mano de obra desde mediados del siglo XVI esclavos negros procedentes de África. No obstante, la situación de opresión en la que vivían estas personas se modificó tras la promulgación del Código Negro, en 1865. A partir de este instante cualquier esclavo podía alcanzar la libertad mediante compra o por medio de la concesión de su amo.

Por otro lado, en esta época nos encontramos con numerosos varones franceses que emigraron al Caribe con la intención de hacer fortuna. Es en este punto donde adquiere especial relevancia el caso de René Dupé, criollo rico elegido como delegado de los comerciantes de la ciudad del Cabo al incendiarse esta población en 1793. A su muerte sus herederos en Francia no lograron certificar su parentesco para cobrar la herencia (al quemarse los textos concernientes a este asunto, las Actas Públicas, durante el incendio de la ciudad). El único testimonio con el que contaban eran las cartas que René Dupé enviaba a su cuñado y se decidieron a hacer la "Declaración de herederos" a partir de la existencia de aquellas.

En cuanto a los artículos de María Dolores Pérez Murillo, son éstos:

- "Emigración de catalanes a Cuba a comienzos del siglo XIX”, Trocadero: Revista de historia moderna y contemporánea, ISSN 0214-4212, n. ${ }^{\circ} 4$ (1992), pp. 145-155.

- “Otras fuentes para el estudio de la Historia de América Latina. Ejemplo metodológico de oralidad e historia de vida”, n. ${ }^{\circ}$ 10-11 (1998-1999), pp. 237-252. 
- "Historia de vida, de familia y de género sobre la emigración a Brasil a comienzos del siglo XX: desde la Andalucía del minifundio a los cafetales de Sao Paulo”, n. ${ }^{0}$ 14-15 (2002-2003), pp. 143-157.

- "La memoria oral como fuente para el estudio cualitativo de la emigración ecuatoriana a los EE. UU. de Norteamérica a finales del siglo XX”, n. ${ }^{\circ} 16$ (2004).

- "Similitudes de los procesos migratorios americanos a través de la historia oral: el caso de Andalucía Oriental”, n. ${ }^{\circ} 19$ (2007), pp. 155-170.

Como hicimos antes con María Magdalena actuaremos ahora con María Dolores Pérez Murillo: elegiremos como muestra uno de sus artículos para proceder a un breve repaso sobre su contenido. En este caso, abordaremos la reseña "Otras fuentes para el estudio de la Historia de América Latina. Ejemplo metodológico de oralidad e historia de vida”. Este trabajo pretende una Historia de América subjetiva sobre los "nadies", los olvidados por la historia oficial, escrita casi siempre por los blancos, la clase dirigente en Latinoamérica desde los primeros tiempos de la colonización hispanolusa.

El interés de nuestra investigadora por la oralidad, eje en torno al que gira el presente artículo, arranca en 1992, cuando nace en la autora el propósito de conocer la "historia de vida” de su padre, Francisco Pérez Pérez, recién fallecido el 30 de enero de dicho año, quien siendo niño, en 1914, emigró con su madre y su hermana menor a San Miguel de Tucumán (Noroeste argentino), adonde su padre ya había marchado en 1911. Pérez Murillo pronto averiguó que en su lugar de origen, Motril, todas las familias tenían algún pariente en Brasil o en Argentina. Así, empezó a contactar con familiares de emigrantes, optando por una historia de la emigración andaluza hacia América Latina cimentada en las “historias de vida” de quienes, directa o indirectamente, habían vivido el exilio. En julio de 1993 Pérez Murillo viajó hasta la República Argentina, visitando las ciudades de Buenos Aires, Córdoba, Rosario, San Miguel de Tucumán y Salta. Allí entrevistó a numerosos parientes y paisanos emigrados en los años 50 del siglo XX, residiendo incluso en las casas de los propios informantes, lo que le permitió cumplir con una de las normas básicas de la Antropología Cultural, la “observación participante”.

A Guerrero Cano y a Pérez Murillo les siguen con tres artículos los siguientes historiadores: Ramón de Armas (Centro de Estudios Martianos de La Habana), María del Mar Barrientos Márquez (Universidad de Cádiz), David Fernández Fernández (Universidad de Cádiz), Beatriz Vitar Muksdi (Centro Superior de Investigaciones Científicas (CSIC), Madrid) y Alberto J. Gullón Abao (Universidad de Cádiz).

Con dos reseñas están: Fernando L. García de Sola Márquez, Juan Aquilino Cascón Becerra, María Dolores Fuentes Bajo y Esmeralda Broullón Acuña, todos ellos de la Universidad de Cádiz.

El resto de los investigadores cuentan en su haber con una sola publicación en Trocadero, pero a pesar de ello creemos que merecen ser mencionados en el presente artículo balance: Áurea Matilde Fernández Muñiz, Susana Bianchi (IEHS, UNCPBA), Marisol Dorao (UCA), Juan José López Cabrales, Pedro Moragues Molina, Maximiliano Salinas, Mario García-Guillén, Carmen Ponce Alonso, M. ${ }^{a}$ Carmen Sánchez Jurado y M. ${ }^{\text {a }}$ Mar Sánchez Riobó (UCa), Juan Carlos Romero López (UCA), Raúl Hernández Asensio (UCA, Universidad Andina Simón Bolívar, Quito, Ecuador), María Teresa Luiz (Univer- 
sidad Nacional de la Patagonia “San Juan Bosco”, Sede Ushuaia, Argentina), María José Portela Miguélez (Universidad de Cádiz), José Luis de Rojas (Universidad Complutense de Madrid), Elida Aponte Sánchez (Universidad del Zulia, Venezuela), Jaime Lucio Fernandes Ribeiro (Universidad Fluminense, Río de Janeiro, Brasil), Francisco Tiapa (Instituto Venezolano de Investigaciones Científicas), José M. Pérez Sánchez (UCA), Ana T. Fanchín (Universidad de San Juan), Felicia Chateloin Santiesteban (Universidad de La Habana), Sergio Antonio Corona Páez (Universidad Iberoamericana Torreón, México), M. Cuesta Domingo y F. López-Ríos (Universidad Complutense de Madrid), Alfonso Oñate Méndez (UCA), Blanca Elisa Cabral y Edda O Samudio A. (Universidad de los Andes, Mérida, Venezuela), Leonardo Soares Dos Santos (Universidade Federal Fluminense, Brasil), Manuela Fernández Mayo (UCA), Jorge Victoria Ojeda (Archivo General del Estado de Yucatán, México), Viviana Kluger (Universidad de Buenos Aires, Argentina), Luhé Palma Chazarra (Instituto Andaluz de Criminología, Universidad de Sevilla), Sigfrido Vázquez Cienfuegos, Violeta Rojo, Gloria de los Ángeles Zarza Rondón, Gloria Espigado Tocino (UCA), Emilio Soler Pascual, GRUPO INDIANO (Ana María Fernández Zampaña, Encarnación de la Pascua Sánchez, María Isabel Marmolejo López, J. Manuel de la Pascua Sánchez, Isabel Ramírez Rodríguez y María de los Ángeles Vicenti Alconchel), GRUPO INTRAHISTORIA (Diego Benítez Mota, Montserrat Forero Fernández, Pilar Gómez Hernández, Antonio J. López Padial, Nieves Macías Delgado, Juan Moreno Nieto y María Dolores Pérez Murillo, UCA), Dra. Miriam Fernández Sosa, Justo L. Del Río Moreno y Francisco Piniella Corbacho.

Si atendemos a una clasificación de los trabajos en cuanto al país o región del continente americano al que hacen referencia, obtendremos los siguientes resultados: veinticuatro sobre España (Cádiz, Diario de Cádiz, Granada, Andalucía, gallegos, catalanes, Andalucía Oriental...) y su relación con Latinoamérica (durante el período colonial o después de la emancipación de las repúblicas latinoamericanas); en relación con la República Argentina (Buenos Aires, Río de la Plata, San Miguel de Tucumán, valle de Cuyo, Virreinato del Río de la Plata), trece reseñas; doce artículos que aluden a Cuba y/ o a su capital, La Habana; diez referidos al conjunto de América Latina; cinco acerca de la actual República Dominicana (Santo Domingo); cinco publicaciones sobre Chile; cuatro ambientadas en Brasil y/ o la ciudad de Sao Paulo; cuatro sobre la relación entre EE. UU. y Latinoamérica y/ o su vecino México; cuatro artículos contextualizados en Venezuela (Maracaibo, delta del Orinoco); tres relativos a México (Virreinato de la Nueva España, Nueva Galicia); tres referentes al conjunto de las Antillas; dos sobre Haití (Saint Domingue); uno sobre la República del Ecuador; uno acerca de Perú (Lima); uno sobre Nicaragua; uno sobre Filipinas - tengamos presente que las islas Filipinas formaron parte del Imperio Español, al igual que los actuales estados hispanoamericanos, desde finales del siglo XVI hasta su independencia e incorporación a EE. UU. en 1898, de ahí que también sean objeto de nuestro análisis - y otro sobre la relación Europa/ América Latina.

Otro tipo de ordenación de los trabajos que podríamos hacer se referiría al marco cronológico al que se circunscriben aquellos. De este modo, tendríamos un título referido a los siglos XV-XVI, el de Justo L. Del Río Moreno “Comercio trasatlántico y comercio regional ganadero en América (1492-1542)”, n. ${ }^{\circ}$ 6-7 (1994-1995). A su vez, contamos con dos artículos contextualizados en el siglo XVI: "La nobleza indígena de 
México ante la conquista española”, n. ${ }^{0}$ 19, pp. 55-68, de José Luis de Rojas e “Interrogantes sobre la relación hombre-mujer dentro del matrimonio en el siglo XVI a través de tres cartas de emigrantes radicados en México”, n. 4 (1992), de David Fernández Fernández.

Referidos al período colonial (siglos XVI al XVIII) tenemos otros dos artículos. Reseñas que aluden al período comprendido entre el siglo XVI y el XIX sólo tenemos una, la de María Magdalena Guerrero Cano "Creación y desmantelamiento de la iglesia metropolitana de Santo Domingo (1547-1802)”, n. 4 (1992).

Artículos que se refieren a la etapa siglo XVI-siglo XX tan sólo tenemos el de Mario García Guillén “500 años de emigración española a Brasil”, n. o 10-11, pp. 201-214.

Sobre los siglos XVII y XVIII contamos con la recensión de Ana T. Fanchín titulada "Senderos de la historia de la familia en los valles cuyanos (siglos XVII-XVIII)", n. ${ }^{\circ} 19$ (2007), pp. 229-242.

Para el siglo XVIII disponemos de doce artículos. A modo de ejemplo citaremos uno de ellos, "Sobre la justicia en la etapa hispánica. El caso de Maracaibo", n. o 14-15, pp. 49-61, obra de María Dolores Fuentes Bajo.

Otros dos trabajos se ciñen a los siglos XVIII y XIX. Nombraremos el de Jorge Victoria Ojeda “Un líder de la revolución haitiana en Cádiz”, n. ${ }^{\circ} 17$ (2005).

Para el siglo XIX son nada menos que quince los trabajos del área de América. Por ejemplo, el artículo de Beatriz Vitar Muksdi “Mujeres, masonería y revolución en Filipinas (1896-1897)”, n. ${ }^{\circ} 17$.

Sin embargo, los escritos referidos al siglo XX representan la gran mayoría, con un total de veinticuatro. A este respecto, citaremos el trabajo de Esmeralda Broullón Acuña "La memoria despierta. Un ejemplo de los barcos de la emigración”, n. 16 (2004).

Para concluir, un único artículo se refiere a los siglos XX y XXI, el de Elida Aponte Sánchez "Las mujeres venezolanas y las revoluciones: la historia que se escribe hoy”, n. ${ }^{\circ} 19$ (2007), pp, 187-198.

Otro tipo de distribución que podemos realizar sobre todo este conjunto de artículos sobre América sería en orden a bloques temáticos. Hemos dispuesto un total de veintisiete bloques temáticos, para un conjunto de setenta y dos artículos. A este respecto conviene aclarar que un mismo artículo puede abordar varios temas al mismo tiempo, como materia principal o secundaria. Seguiremos con la misma tónica de antes: expondremos cuáles son eses ejes temáticos principales, cuántas reseñas pueden adscribirse a dichos ejes y para cada caso citaremos un artículo como ejemplo.

El bloque temático al que se ha dedicado un mayor número artículos, un total de quince, es el de Migraciones (Emigración española a Brasil, Emigración ecuatoriana a EE. UU., Inmigrantes sirios y libaneses, Barcos de la emigración, Sueño americano, Frontera, Emigrantes andaluces residentes en Argentina, Emigrantes catalanes, Indianos, Migraciones de latinoamericanos a España, Cádiz: plataforma de la emigración a Indias). Como ejemplo mencionaremos el artículo de Beatriz Vitar Muksdi (CSIC, Madrid), "Inmigrantes sirios y libaneses en Tucumán (Argentina). El reclamo de la etnicidad”, Trocadero n. ${ }^{\circ}$ 10-11, pp, 287-308.

Otro tema muy tratado ha sido el de Política y Pensamiento Político (José Martí, Política colonial, Peronismo, Populismo, Socialismo, Dictadura, Comunismo), con un 
total de once artículos. Ejemplo: “Catolicismo y Peronismo. Iglesia católica y estado en la Argentina, 1945-1955, Trocadero n. ${ }^{\circ}$ 8-9 (1996-1997), pp. 350-367, obra de Susana Bianchi (IEHS, UNCPBA).

Diez son los estudios que hablan acerca de Oralidad e Historias de Vida, como por ejemplo "La solidaridad con Nicaragua en la década de los ochenta a través de testimonios orales”, de Juan Carlos Romero (UCA).

Sobre Conquista y Colonización (Expediciones, Jesuitas, Diplomacia, Conquista española, Sometimiento indígena, Guerra de frontera) nos encontramos con ocho trabajos, entre ellos “Guía y vademécum del conquistador” de los autores M. Cuesta Domingo y F. López Ríos (Universidad Complutense de Madrid).

También ocho han sido los artículos que han abordado el tema del Género (Mujer, Cárceles de Mujeres, Relación hombre-mujer), entre ellos “El Género, una categoría de análisis crítico que nos cuenta otra Historia”, de Blanca Elisa Cabral y Edda O Samudio A. (Universidad de los Andes, Mérida, Venezuela).

En cuanto a las obras sobre Economía (Agricultura, Ganadería, Comercio), siete han sido las que han tocado este tema. Una muestra de ello la obtenemos en "Viñedos y cosecheros privilegiados por los Borbones en la Nueva Vizcaya de la Nueva España”, de Sergio Antonio Corona Páez (Universidad Iberoamericana Torreón, México).

Acerca de la materia que hemos titulado Movimientos Sociales y Derechos Civiles (Ligas campesinas, Excluidos, Lucha de clases, Grupos populares urbanos, Sociedades secretas, Masonería), igualmente contamos con siete publicaciones, una de las cuales es "No llores por él Argentina (Lucha de clases versus Populismo)”, de Pedro Moragues Molina.

Otro eje temático sería el de Historia Social/ Sociedad (Occidentalización, Solidaridad, Aspectos culturales, sociales, económicos y religiosos), con seis artículos a su vez, como por ejemplo: “Tarzán de los monos: una utopía americana del siglo XX”, a cargo de Marisol Dorao (UCA).

Otros tantos artículos, seis, versarían sobre Frontera ((Forma de vida, Concepto de Frontera). Ejemplo: "La frontera como forma de vida y el paso del sueño americano a la pesadilla urbana: representación en el cine”, obra de José M. Pérez Sánchez (UCA).

Etnicidad y Etnografía sería un nuevo bloque. En este caso hemos encontrado hasta cinco artículos que estudian este asunto, uno de los cuales es el trabajo de Helga Neumayer "Algunos datos acerca de la cultura afro-dominicana del siglo XVIII y una comparación etnográfica contemporánea”.

Por otra parte, cinco son los estudios que analizan la materia Iglesia y Evangelización (Iglesia Católica y Estado, Iglesia de base, Jesuitas, Teología de la Liberación), siendo susceptible de ser citada aquí la obra de David Fernández Fernández (UCA) "La iglesia de base chilena vista con ojos de mujer. Perspectiva histórica a través del testimonio de Francisca Morales”.

Otras tres materias que cuentan con dos artículos son las tituladas Revoluciones - caso de “Un líder de la revolución haitiana en Cádiz”, de Jorge Victoria Ojeda (Archivo General del Estado de Yucatán, México) - , Marginación (Cárcel, Esclavitud, Prostitución) - "La prostitución en La Habana en los primeros años del siglo XX”, de Alberto J. Gullón Abao (UCA) - y Administración (Justicia, Derecho, Procesos Judi- 
ciales, Justicia local, Derechos civiles) - "Sobre la justicia en la etapa hispánica. El caso

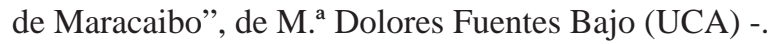

Con cuatro ejemplos hallamos las materias Familia (Historia de la Familia, Genealogía, Estrategia matrimonial) y Cultura (Música, Teatro, Literatura, Herencia cultural). Un prototipo de artículo sobre Familia sería "Historia de vida, de familia y de género sobre la emigración a Brasil a comienzos del siglo XX: desde la Andalucía del

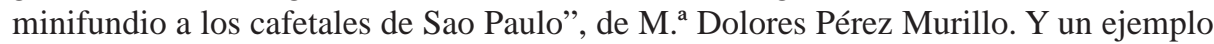
de artículo sobre Cultura lo encontramos en "Realismo mágico, Historia e Intrahistoria en el cine iberoamericano”, de Juan Aquilino Cascón Becerra (UCA).

Sobre Élites (Nobleza indígena, Colegio de nobles americanos), Cine (Cine norteamericano, Cine iberoamericano) y Carrera de Indias (Oficiales de la mar, Comercio gaditano), igualmente hemos localizado tres artículos para cada uno. Acerca de Élites "La estrategia matrimonial en la élite del Partido Unión Constitucional de Cuba, 18301860”, debido a María José Portela Miguélez (UCA). En relación con Cine “El cine como fuente para la historia, Iberoamérica y el cine norteamericano" (Juan Aquilino Cascón Becerra, UCA). Y sobre Carrera de Indias "Los oficiales de la mar andaluces de

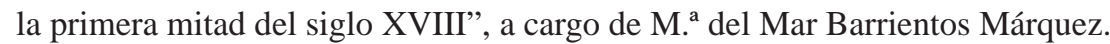

A continuación sigue una amplia lista de temas cuya representación se limita a tan sólo dos artículos:

- Vida cotidiana: "Senderos de la Historia de la Familia en los valles cuyanos (siglos XVII-XVIII)”, de Ana T. Fanchín (Universidad de San Juan, Argentina).

- Arquitectura: "El plan maestro de La Habana vieja: contexto y propuestas”, de Juan José López Cabrales.

- Prensa (Diario de Cádiz): “La "vía chilena al Socialismo” a través del Diario de Cádiz”, de Fernando L. García de Sola Márquez (UCA).

- Testamentos (Documentación protocolaria): "Los oficiales de la mar andaluces de la primera mitad del siglo XVIII”, de M. ${ }^{a}$ del Mar Barrientos Márquez (UCA).

- Historia de las Mentalidades: “Interrogantes sobre la relación hombremujer dentro del matrimonio en el siglo XVI a través de tres cartas de emigrantes radicados en México”, de David Fernández Fernández.

- Historiografía: "La integración latinoamericana en la historiografía cubana: el caso de la Confederación Antillana”, de Ramón de Armas.

Por último, con un solo artículo tenemos tres temas: Transportes - "La introducción del vapor en el sistema colonial español de comunicaciones marítimas: 18481850”, de F. Piniella Corbacho - Expediciones científicas (Ilustración) - “Alejandro Malaspina, un ilustrado español en la costa norte del Pacífico (1791)”, de E. Soler Pascual - y Globalización y Multiculturalidad - "Las identidades multiculturales”, de Esmeralda Broullón Acuña (UCA).

A continuación, nos gustaría detenernos en la Revista Trocadero número 4 (1992), pues se dedicó en su totalidad a un estudio monográfico sobre la relación entre Cádiz y América, en conmemoración del Quinto Centenario del Descubrimiento de América por Cristóbal Colón en 1492. Así pues, pasaremos a realizar un pequeño 
comentario acerca de todos los artículos que compusieron ese número 4 de nuestra revista.

El primero de ellos se titula "Escuela de Comercio del Consulado Gaditano", Trocadero n. ${ }^{\circ} 4$ (1992), pp, 7-20, y su autora es María del Mar Barrientos Márquez. En este estudio la Profesora Barrientos se hace eco de la construcción de la Escuela de Comercio en Cádiz, a raíz de la Real Orden de 1799, según la cual se implantan en el Consulado de Cádiz, así como en el resto de consulados españoles, las “enseñanzas de comercio". Las clases de comercio iban a dar comienzo en nuestra ciudad en un principio en 1804, pero debido a una serie de contratiempos, como el estallido de la guerra contra Inglaterra, la aparición de un brote de fiebre amarilla en Cádiz y, más tarde, el conflicto de la Guerra de Independencia Española (1808-1814) - incluido el asedio de Cádiz por las tropas napoleónicas - retrasarían el inicio de las clases hasta el mes de enero de 1819.

La Escuela de Estudios Mercantiles de Cádiz habría de ubicarse en el número 68 de la Calle San Francisco, esquina Aduana Vieja, de la capital gaditana. La restauración del edificio que iba a albergar dicha escuela fue dirigida por el arquitecto Don Pedro Ángel de Albisu, dando comienzo las obras el dos de enero de 1804 y concluyendo las mismas el veintidós de septiembre de 1806. Todos los gastos corrieron a cargo del Consulado de Comercio de Cádiz.

El objetivo de la Escuela de Estudios Mercantiles no fue otro que el de preparar convenientemente a los futuros comerciantes gaditanos. Para ello, se les impartirían materias tales como Matemáticas, Relaciones comerciales entre España y el extranjero, Legislación Mercantil en España y en el exterior e idiomas (francés, inglés y toscano).

El siguiente artículo de esta revista 4 corresponde a Áurea Matilde Fernández Muñiz y se titula "Los indianos: su incidencia en la economía peninsular y en la política colonial”.

En primer lugar, debemos aclarar que con el término “indiano” se conoce a los emigrantes españoles que se volvieron ricos y poderosos en Cuba con anterioridad a la Guerra de $\mathrm{Cuba}^{3}$. Sin embargo, la realidad de los indianos fue otra y la mayoría de ellos no consiguió enriquecerse, pero si al menos introducir una buena cantidad de dinero en la metrópoli, España. A raíz del estallido del mencionado conflicto, los indianos reaccionaron de diferentes maneras: por un lado, tenemos a los que deciden regresar a la Península Ibérica, por temor a la guerra; otros, en cambio, deciden enviar grandes cantidades de dinero a los suyos; y también están los que adquieren nuevas propiedades en la isla de Cuba, aprovechando estos momentos de inestabilidad; y también quienes dejan sus tierras en la isla caribeña en manos de apoderados, para que las cuiden en su lugar. En definitiva, nos encontramos con un sinfín de situaciones que sirven para elevar, en la sociedad española previa a la Restauración, a la categoría de burguesía ascendente a los hombres “con posibles”, los indianos. Pongamos como ejemplo al Marqués de Comillas, propietario de la Trasatlántica, a quien iban a beatificar incluso tras haber acumulado una muy caudalosa fortuna por medio del tráfico de esclavos negros, que adquiría en África y traía a América.

En definitiva, en este estudio la investigadora Fernández Muñiz intenta destacar la actitud de algunos indianos, que aprovecharon la coyuntura de la Guerra Grande para lucrarse. 
A este artículo le sigue otro de Emilio Soler Pascual, bajo el título de "Alejandro Malaspina, un ilustrado español en la costa norte del Pacífico (1791)”, pp. 37-59. La expedición de Alejandro Malaspina obedece a la política, ya iniciada en la época de Carlos III de España (1759-1788), de grandes viajes marítimos para favorecer la presencia española en el Pacífico Norte y en el Atlántico Sur. Estas expediciones también contribuyeron a la incorporación al imperio español de nuevos territorios. Así, fue posible la colonización de la Alta California y el comienzo del poblamiento de la Patagonia y de las Malvinas. Si a esto le sumamos las incorporaciones debidas a guerras y a tratados políticos, nos encontramos con que durante el reinado de Carlos III los dominios españoles en América alcanzaron su extensión máxima.

Sin embargo, un imperio tan extenso y tan lejano de la metrópoli, España, resultaba muy difícil de defender. Tras los ataques sufridos a manos de los ingleses en numerosas plazas fuertes americanas - Santiago de Cuba, Cartagena de Indias, Sacramento, Buenos Aires - la monarquía hispánica se decidió a fortificar las costas de su amplísimo imperio.

En lo que respecta a Alejandro Malaspina (1754-1810), decir que fue un marino italiano al servicio de España. Su famosa expedición zarpó de Cádiz en 1789, regresando a dicho puerto en 1794 después de haber recorrido las costas del Río de la Plata, la Patagonia, las islas Malvinas, la Tierra del Fuego, Chile, Perú, Ecuador, Panamá, México, California, Alaska, Canadá, las islas Marianas, las Filipinas, Australia y Tonga. La expedición científico-política de Malaspina contribuyó a certificar la inexistencia en la costa norte de América de un supuesto paso entre el Atlántico y el Pacífico - el famoso "Paso del Noroeste" - , así como para perfeccionar la cartografía costera de amplios territorios pertenecientes a la corona española.

Alejandro Malaspina siempre se mostró partidario de acabar con la política monopolista española en materia de comercio, que prohibía el tráfico interregional en América. En su opinión, había que seguir el mucho más pragmático modelo colonial inglés, basado en el dominio de unos pocos enclaves estratégicos, dejando el resto del territorio bajo el gobierno de las poblaciones aborígenes, frente al modelo español, que se cimentaba en la dominación política, el control mercantil y la extracción de metales preciosos.

En 1796 Malaspina fracasará en una conspiración contra Godoy (primer ministro de Carlos IV de España entre 1792 y 1797 y también entre 1801 y 1808), siendo condenado a prisión y más tarde, en 1802, al exilio.

El siguiente artículo corresponde a la investigadora Helga Neumayer y responde al título "Algunos datos acerca de la cultura afro-dominicana del siglo XVIII y una comparación etnográfica contemporánea”, pp. 61-70. En este análisis se detalla la cotidianidad de la población negra en la colonia española de Santo Domingo durante el siglo XVIII (actual República Dominicana). En el conjunto de esa población de raza negra Helga Neumayer diferencia entre una serie de realidades bien distintas:

- Esclavas y esclavos domésticos y jornaleros: en las ciudades los esclavos eran destinados al trabajo doméstico, o bien eran alquilados por sus amos a cambio de un jornal. Así, las esclavas eran obligadas por sus propietarios a prostituirse.

- Esclavas y esclavos de plantación: en la centuria del Setecientos la colonia española de Santo Domingo aún no contaba con un floreciente siste- 
ma de agricultura de plantación. Los esclavos africanos aún eran escasos y por ello los amos trataban de fomentar la procreación endógena de los mismos. En este context,o Neumayer sitúa a los "bancos de muerto", tradición funeraria africana que ya se constata en la colonia de Santo Domingo en el XVIII y que pervive aún hoy en día en el sur de la República Dominicana.

- Esclavos hateros: éstos vivían aislados en hatos y hatillos, esto es, ganaderías extensivas de cerdos y vacas que existían en toda la colonia de Santo Domingo durante el siglo XVIII.

- Cimarrones, esclavas y esclavos alzados: huidos del sistema esclavista, se refugiaban en los espesos bosques de las montañas de la isla, para habitar en un maniel o asentamiento. En el siglo XVIII la Sierra del Bahoruco, ya entonces frontera entre las colonias francesa (la actual Haití) y española (Rep. Dominicana), sirvió de refugio para los esclavos de una parte y otra de la isla.

Podemos concluir que todas estas realidades negras se transformaron a partir de una serie de sucesos que sobrevinieron en el siglo XIX, como la revolución haitiana, la abolición de la esclavitud y la sustitución de la ganadería como principal actividad económica por la agricultura intensiva de azúcar, cacao, café y tabaco y por el comercio de madera preciosa. No obstante, ciertas creencias religiosas y tradiciones musicales de las colectividades negras del XVIII dominicano han pervivido hasta la actualidad.

Le sigue al artículo de Helga Neumayer otro de Alberto J. Gullón Abao, profesor de la Universidad de Cádiz, que se titula "La Gobernación del Tucumán en la primera mitad del siglo XVIII. Coacciones y reacciones ante una guerra de frontera”, pp. 7184. Comienza el Dr. Gullón diciendo que, durante los tres siglos del período colonial (XVI al XVIII), el Chaco ${ }^{4}$ vivió una continua vida de frontera, debido a la guerra entre españoles e indígenas - tobas, mocovíes, abipones... -. Los españoles, provenientes del Perú, se instalaron en los valles próximos a la cordillera, fundando ciudades como Salta, Jujuy, San Miguel de Tucumán, Santiago del Estero, La Rioja, Catamarca o Córdoba. Estos colonizadores buscaron en todo momento consolidar sus asentamientos, extender la frontera y capturar indios para ponerlos a trabajar en haciendas y obrajes. Por su parte, los indígenas trataron de preservar sus tierras, asaltando las ciudades, haciendas y caravanas de los blancos.

Ante la ausencia de un ejército regular, la defensa de la Gobernación del Tucumán recayó en los pobladores blancos y mestizos (encomenderos y moradores), quienes debían aportar víveres, armas y caballos a su propia costa para la lucha contra el indio. Pero siempre hubo objeciones a las convocatorias a emprender acciones bélicas contra los chaqueños. Ante los incumplimientos de órdenes, las autoridades españolas recurrieron a castigos de diversa índole:

- Corporales.

- Económicos.

- Pérdida de cargos públicos.

- Degradaciones.

- Destierros en los fuertes de la frontera. 
Podemos concluir que, en ocasiones, los pobladores de este territorio de la actual Argentina dejaban de ir a la guerra no sólo por el riesgo para sus vidas que ello suponía, sino también por el coste económico de los conflictos, que no sólo se limitaban a los gastos de campaña (armas, provisiones, bestias...), sino que a las expediciones también debían acudir con sus indios, de tal manera que sus haciendas y ganados quedaban sin brazos que cuidaran de ellos.

“Cádiz: Plataforma de emigración a Indias. 1750-1760”, pp, 85-110, es el titular elegido por el Grupo Indiano para nombrar su trabajo, que en esta ocasión se ocupa de la emigración a Indias entre 1750 y 1760, usando como fuente fundamental para su estudio los fondos del Archivo Histórico Provincial de Cádiz (sección Protocolos) y los del Archivo General de Indias de Sevilla (sección Ultramar). Así pues, recurriremos a los fondos notariales y a las licencias de embarque (que nos hablan sobre la emigración legal a Indias). El número total de documentos es de 2784: 2156 son poderes ${ }^{5}$ (un $77 \%$ de la documentación), 368, testamentos ${ }^{6}, 220$ licencias $^{7}$ y 40 prorrogaciones $^{8}$. Las licencias de embarque, obtenidas en el Archivo de Indias, nos valieron para contrastar los datos conseguidos en las fuentes notariales. Entre 1750 y 1760 tenemos un total de 3.470 personas, distribuidas en provistos ${ }^{9}$, cargadores $^{10}$ y pasajeros ${ }^{11}$.

El Grupo Indiano en el presente artículo va a analizar una serie de cuestiones en torno a los emigrantes a Indias entre 1750 y 1760: su naturaleza, vecindad y residencia; su estado civil, profesión y destino.

Decir que de la documentación inventariada hemos conseguido un total de 2023 personas que utilizan el puerto de Cádiz para viajar a América. De éstos, 1228 (un 60,7\%) no especifican su procedencia, 286 (un 36\%) son de Andalucía occidental, 115 del País Vasco y Navarra y 100 extranjeros. La fuerte presencia de andaluces en la emigración trasatlántica es una constante desde el siglo XVI. En el XVIII un 39\% del total de emigrantes son andaluces, como consecuencia de la condición de Cádiz (desde 1717) de sede del monopolio del comercio con América. La causa de esta constante emigración andaluza a Indias es la existencia de una gran masa de proletariado agrícola sin tierras, que vive al límite de la subsistencia ${ }^{12}$.

En lo que se refiere al estado civil de los embarcados, un 66,5\% del total son solteros (es decir, 1345 individuos: 295 solteros y otros 1050 que no lo especifican pero que pueden ser considerados como tales), mientras que los casado son el $31 \%$ del total (630).

En cuanto a su profesión, un 59,4\% (1203) no dicen su oficio, probablemente porque no tenían ningún tipo de cualificación profesional.

Por lo que se refiere al destino de estos emigrantes, unos 855 de ellos (el 42\%) se dirigirán al virreinato de Nueva España (puerto de Veracruz).

Podemos comprobar en este estudio cómo el total de personas que aparecen en el Archivo de Protocolos de Cádiz (2023 individuos) significan el 58\% de los 3470 que viajaron de forma legal a las Indias entre 1750 y 1760. Finalizamos el análisis del presente artículo incluyendo aquí una ficha tipo del emigrante que embarcó en Cádiz hacia las Indias en el período 1750-1760: 


\begin{tabular}{|c|c|}
\hline Sexo......... & Varón \\
\hline 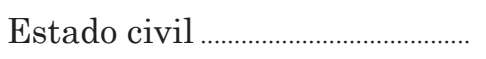 & Soltero/ recién casado \\
\hline Edad..... & $25-40$ años \\
\hline Procedencia......... & Andalucía Occidental \\
\hline Profesión ............................. & Sin oficio \\
\hline Motivo del viaje & Buscarse la vida \\
\hline Duración ...................... & Sin límite de tiempo \\
\hline Destino & Nueva España \\
\hline 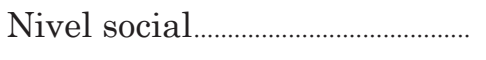 & Medio/ bajo \\
\hline Documento otorgado.. & Poder/ testamento \\
\hline
\end{tabular}

El próximo estudio corresponde al investigador David Fernández Fernández y lleva por nombre "Interrogantes sobre la relación hombre-mujer dentro del matrimonio en el siglo XVI a través de tres cartas de emigrantes radicados en México”, pp. 111-120. Aquí vamos analizamos tres cartas que mandaron a sus respectivas esposas tres emigrantes españoles situados en México en la segunda mitad del siglo XVI ${ }^{13}$. Las cartasreclamo ${ }^{14}$ acompañaban a algunas solicitudes de embarque para demostrar que algún pariente o paisano instalado en América iba a acoger al nuevo emigrante que deseaba marcharse de España. Las tres cartas que hemos escogido para este trabajo son:

- De Sebastián de Montes de Oca a su mujer María de Fuentes, en Sevilla, con origen y fecha de México, 15-II-1563.

- De Luis de Illescas a su mujer Catalina Gutiérrez, en Jerez de la Frontera. México, 24-IX-1564.

- De Antonio de Blas a su mujer Leonor Bernal, en Sanlúcar, México, 1-XI-1566.

De la primera carta extraemos el siguiente fragmento: "Busque compañía con quien venga, y si no hallare, venga sola, que mujer es para mirar por su honra..." Sebastián de Montes de Oca hace de su mujer la valedora y defensora de su honra. Confía en su fidelidad, a pesar de lo peligroso de un viaje transoceánico en el siglo XVI para una mujer sola. Ésta es una carta emotiva y tierna, que denota un estrato social más humilde que el de las otras dos cartas. El amor es el eje de la epístola. Parece que lo afectivo tenía más cabida en los ambientes populares. Como sostiene Saavedra Fajardo "a los nobles pertenece el honor y al pueblo la libertad"15.

En lo que atañe a la carta de Luis de Illescas, éste le exige a su mujer que se vaya con sus hijos a México, dónde está él: "se venga con toda su casa a esta tierra, porque yo no pienso de ir en mi vida a esa". Para el viaje le aconseja que busque buena 
compañía. La carta gira en torno a lo económico y al honor, de tal manera que la mujer aparece como incapaz de cuidar de su propia honra, que no es sino la honra del esposo proyectada sobre ella.

En cuanto a la misiva de Antonio de Blas a su esposa, muestra una gran preocupación por el honor (lo aparente) y por la riqueza (lo material). Así, escribe: “y mira cómo venís, venid en compañía de un hombre casado, que vengáis mucho a vuestra honra (...) no hay mayor riqueza en el mundo que es la honra”. En el siglo XVI el honor es la clave de la articulación social y en el vientre de la mujer depositaron el honor. Uno-a es lo que se espera que él-ella sea. También dice en la carta: "los primeros reales que gastarades sea en una negra, para que os sirva por el camino”. Aquí se refleja la posición acomodada de Antonio de Blas y su preocupación por la riqueza. Continúa de Blas: "en esta vida no tengo otro descanso sino a vos, ni tengo otro deseo". La función que este individuo otorga a su esposa es la de descanso y deseo.

Le sucede al artículo de David Fernández otro cuya autoría corresponde a Ramón de Armas y que lleva por título "La vanguardia antillana de la segunda mitad del siglo XIX y la estrategia revolucionaria continental de José Martí”, pp. 121-144. Desde la segunda mitad del XIX el Panantillanismo, la idea de una confederación de las islas antillanas, fue recorriendo el Caribe como forma de salvaguardar estos territorios de las viejas potencias coloniales europeas y de la nueva potencia en auge, los Estados Unidos de Norteamérica. En ese momento aparecieron en el escenario político antillano hombres que perseguían ambos objetivos en sus proyectos revolucionarios, así como la consecución de la emancipación de cientos de miles de esclavos negros en Cuba y Puerto Rico. Entre otros, estos hombres fue-

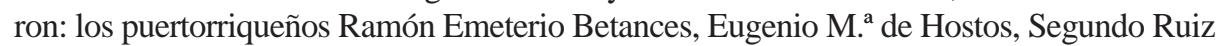
Belvis y Francisco Basora; los dominicanos Gregorio Luperón, Ulises Espaillat, José M. ${ }^{\text {a }}$ Cabral y Pedro F. Bonó; los haitianos Nissage Saget, Fabre Geffrard; Louis Joseph Janvier y Antenor Firmin; y los cubanos Juan Manuel Macías, Francisco Vicente Aguilera, Antonio Maceo, Máximo Gómez (cubano y dominicano) y José Martí. Ésta es la que se conoce como la vanguardia revolucionaria antillana de la segunda mitad del XIX.

Características comunes de los iniciadores del panantillanismo serían:

1. Reconocimiento de que las islas antillanas están dotadas de unidad geográfica, histórica, cultural, nacional y étnica.

2. La necesidad de unión de todos los territorios que componen el conjunto para defenderlo y también para lograr un progreso más rápido individual y colectivo de sus entidades.

3. El alto grado de compromiso con los grupos sociales más oprimidos y desposeídos de las sociedades antillanas: los esclavos negros.

El caso de José Martí ha sido el más estudiado porque en él confluyeron mayores posibilidades de proponer una estrategia revolucionaria continental, cuyas soluciones hasta hoy siguen teniendo vigencia. Martí pretende una unión defensiva de las Antillas, sobre todo frente a los nuevos mecanismos de penetración económica que desde la primera mitad de la década de 1890 EE. UU. está poniendo en práctica en México, Rep. Dominicana y - a través de España - en Cuba y Puerto Rico. Así, anticipa que en Cuba se instalarán, con capital estadounidense, muchas empresas que ocasionarán una gran demanda de artículos procedentes del único mercado donde Cuba tendrá crédito y 
dinero, esto es: EE. UU. Como vemos, José Martí no pudo prever con mayor acierto el futuro que le esperaba tanto a Cuba como a toda América Latina.

Le llega el turno ahora al artículo de M. ${ }^{a}$ Dolores Pérez Murillo "Emigración de catalanes a Cuba a comienzos del siglo XIX”, pp. 145-155, el cual forma parte de una investigación más amplia, referida a la emigración legal de españoles a Cuba, a partir de la consulta de los permisos de embarque que para el XIX se guardan en el Archivo General de Indias de Sevilla, en las secciones de Santo Domingo y Ultramar. Con respecto al material consultado, decir que hemos empleado 35 legajos, con una media de 90 licencias de embarque por cada legajo, lo que implica un total de emigrantes legales peninsulares a Cuba de 4000 personas, siendo el total de catalanes de 2475 para los primeros treinta años del XIX. Debemos hacer notar que cada licencia de embarque suele venir acompañada de otros documentos:

1. Una Instancia ${ }^{16}$ dirigida al Rey.

2. El consentimiento (que permite averiguar el nivel de arraigo familiar de un individuo a su país de origen).

3. Certificados de buena conducta.

4. Partidas del Bautismo.

5. La carta familiar-privada, que nos permite acercarnos al mundo de las Mentalidades.

Apuntar asimismo que de 1827 a 1832, ambos inclusive, son los años que registran el máximo de migraciones a Cuba, siendo los catalanes el grupo más numeroso. En lo que concierne a las características de la emigración catalana en Cuba, debemos anotar las siguientes:

1) En 1827 y 1828 los catalanes van a significar el 72\% del total de inmigrantes peninsulares, debido a la depresión económica que vive Cataluña en esos momentos.

2) La mayoría de esos migrantes procede de la zona costera catalana.

3) Casi todos los que emigran a Cuba se dedican al comercio ${ }^{17}$.

4) La extracción social del desplazado catalán es heterogénea.

5) Aquí asistimos a un claro fenómeno de emigración golondrina (muchos emigraban sólo por seis meses ó un año).

En base a todo lo expuesto anteriormente, podemos diseñar una ficha tipo del emigrante peninsular a Cuba para el período 1800-1835: varón, soltero, de entre 10 y 30 años, originario de Cataluña y con La Habana como destino.

Para continuar, decir que nos encontramos en este número especial de Trocadero sobre Historia de América con el artículo de la investigadora de la Universidad de Cádiz Gloria Espigado Tocino titulado: "El comercio gaditano a fines del siglo XIX: análisis de un año de actividad portuaria”. A pesar de que se tiene la concepción de que los viajes a ultramar desde Cádiz descendieron extraordinariamente a lo largo del XVIII, existen diferentes trabajos en los que se rebaten estos argumentos: por ejemplo, Cádiz y el Atlántico del Profesor García Baquero o Cádiz, ciudad revolucionaria de Sánchez-Albornoz, donde se demuestra que en los años centrales del XIX es posible hablar de una visión cíclica y aunque ya no lleguen oro y plata de América a manos llenas, tampoco se puede hablar del infortunio. 
Se documenta un ascenso de las transacciones comerciales en los años 18531854, hasta que el año 1864 comienza a arrojar datos negativos, no pudiendo prolongarse la buena racha comercial más allá del 1870-71. Podemos constatar esto en la prensa local de la época, por ejemplo, en el periódico El Comercio, donde se habla de los países que participan mayoritariamente en las entradas y salidas de barcos. El primero de la lista con diferencia es Inglaterra y los productos que trafican los ingleses son carbón, hierro, bacalao...También aparece un tráfico regular entre Cádiz y Gibraltar. Los segundos en importancia son los franceses y en tercer lugar están los portugueses. A mucha distancia nos topamos ya con el bloque de holandeses, rusos, suecos, daneses, etc. En cuanto a las mercancías con las que se comercia con estas naciones, decir que es relevante el tránsito de carbón, vino, pescado, sardinas, sal,...También hay que destacar las áreas geográficas con las que se mantienen los vínculos, principalmente Europa y el continente americano. Y debido al mantenimiento en manos españolas de la colonia de Filipinas, podemos reseñar un vínculo mercantil con Asia, aunque éste tan solo sea del 1\%. Por último, el artículo dedica un apartado a la figura del consignatario, que aparece definido como el armador de buque que se encarga de los asuntos administrativos, generalmente de clase acomodada. Como consignatarios de buques en Cádiz destacan nombres como Bernardino de Sobrino, de la Compañía de Vapores Sobrino, Antonio de Zulueta o Manuel Cadarso.

En lo que atañe a la recensión de M. ${ }^{a}$ Magdalena Guerrero Cano "Creación y desmantelamiento de la iglesia metropolitana de Santo Domingo (1547-1802)”, decir primeramente que, al descubrirse América en 1492, los Reyes Católicos (RR. CC.) se plantearon la organización de la iglesia indiana. En 1493 el Papa Alejandro VI les concedió la Bula "Inter Caetera”, que confería poder para enviar evangelizadores a las nuevas tierras. En 1511 el Papa Julio II otorgó a la monarquía hispánica el Real Patronato ${ }^{18}$, estableciéndose dos diócesis en la isla de La Española (el primer territorio de colonización hispana de todo el territorio americano), la de Santo Domingo y la de Concepción de la Vega, que quedaron unificadas en la primera en 1528.

Santo Domingo, el primer obispado de las Indias, tuvo un peso más simbólico que real en la evangelización, siendo además dependiente de la jurisdicción metropolitana de Sevilla hasta que en 1546 se desgaja de ella y además, se crean otras tres sedes arzobispales en Indias: Santo Domingo, México y Lima. De Santo Domingo dependían en torno a 1571 tres obispados sufragáneos (Cuba, San Juan de Puerto Rico y Venezuela) y la abadía de Jamaica, así como Camayagua desde 1564 y Cartagena desde 1577.

Desde el comienzo vamos a asistir a una escasez de clérigos en proporción a los fieles: a mediados del XVII existen cuarenta sacerdotes diocesanos (incluyendo a los dieciocho de la catedral) y cuarenta religiosos de las tres órdenes (franciscanos, dominicos y mercedarios) desde el XVI instaladas en la isla. En su organización la iglesia dominicana permanecerá inalterada hasta el XIX. En 1795, por el Tratado de Basilea, se acuerda el paso a Francia de la parte española de la isla. Ante esto, muchos españoles salieron a toda prisa hacia Caracas y La Habana. Todos los organismos oficiales, incluida la catedral, fueron desmantelados, surgiendo el problema de las sufragáneas de Santo Domingo. En 1802 la Cámara de Indias y el Consejo de Indias acordaron que los obispados de La Habana, Cuba, Puerto Rico y Luisiana pasaran a depender del arzobispado de México y los de Caracas y Guayana, de Santa Fe. 
El último documento de esta revista número 4 es el que sigue: "Cuba: Estudios sobre pensamiento político cubano en la historiografía nacional”, pp. 203-213, donde su autora, Miriam Fernández Sosa, alude a las investigaciones llevadas a cabo hasta la fecha - el año 1992 - sobre pensamiento político cubano, dejando bien claro que hasta aquel entonces aún no se había emprendido un estudio integral y totalizador sobre el tema. A continuación haremos un repaso sobre las obras publicadas por la historiografía cubana sobre política. Así, vemos como en la segunda mitad del siglo XIX se escriben biografías acerca de personajes destacados de la historia política cubana, como es el caso de Carlos Manuel de Céspedes.

Durante las dos primeras décadas del XX, a raíz del establecimiento en Cuba de una república dependiente de EE. UU., se publican obras que critican esa supeditación política y económica, como “Cuba heroica” (1912) o "Contra el yanqui” (1913). A lo largo de la década de 1920 y de la primera mitad de 1930 se hacen sentir las primeras manifestaciones de la crisis del sistema neocolonial que EE. UU. había impuesto en Cuba.

A mediados de la década del 30 y a lo largo de la del 40, tras la caída de Gerardo Machado en 1933, surge una élite política que pretende un estado más moderno, pero sin sobrepasar el marco de dependencia neocolonial. Así, ven la luz estudios muy conservadores, como los Cuadernos de La Historia Habanera, sobre Antonio Maceo y Máximo Gómez. Durante la década del 50 el surgimiento de una dictadura militar agudiza las contradicciones entre clases y también la oposición entre el interés nacional y los propósitos de la oligarquía cubana y del imperialismo yanqui (que aceptan a F. Batista).

Después del triunfo de la revolución cubana en 1959, aparecen innumerables trabajos sobre el máximo exponente del ideario nacional antiimperialista, José Martí, como “José Martí: pensamiento y acción” (1982), de Julio Le Riverend. Asimismo, hay estudios sobre el pensamiento cubano en la época de la plantación esclavista y sobre los postulados de Fidel Castro y del Ché Guevara.

Entre 1985 y 1989 el Departamento de Historia de Cuba de la Facultad de Filología e Historia de la Universidad de La Habana publicó seis tomos de una Antología de Historia del Pensamiento Político Cubano, dos referidos a la etapa colonial y los cuatro restantes (precisamente de M. Fernández Sosa) dedicados a la república neocolonial.

Como conclusión final del presente trabajo de síntesis, podemos hacer ver cómo a lo largo de todos estos años de investigación histórica, el área de

Historia de América del Departamento de Historia Moderna y Contemporánea de la Facultad de Filosofía y Letras de la Universidad de Cádiz (UCA) ha ido diversificando sus temas de estudio, evolucionando desde materias como Historia Económica, Iglesia, Conquista y colonización o Sociedad, hasta otras como Historia Oral, Migraciones, Género, Cine o Frontera, que están más en boga en la actualidad.

Desde aquí queremos resaltar la trascendencia que deben tener los estudios americanistas dentro de la docencia y de la investigación histórica, y más aún si cabe en un país como España y en una ciudad como Cádiz, muy estrechamente vinculadas en su devenir histórico a América Latina. Es más, podemos decir sin temor a equivocarnos que nuestro pasado, nuestro presente e incluso nuestro porvenir no pueden entenderse sin tener en cuenta la realidad de los países latinoamericanos, con los cuales nos unen 
lazos raciales, lingüísticos, económicos, culturales y sociales. De ahí el importante papel que entendemos debe desempeñar la Historia de América en el Departamento de Historia Moderna y Contemporánea de la Universidad de Cádiz.

Aprovechamos la ocasión para desear que la Revista Trocadero pueda proseguir muchísimos años más su intensa labor de investigación y divulgación científica, en la cual la cooperación y la sincronía entre las distintas áreas de nuestro departamento debe ser una máxima de obligado cumplimiento. Asimismo, queremos felicitar a todo el personal de la revista y a todos los autores que han publicado sus trabajos con nosotros durante estos veinte años por su esfuerzo y dedicación, animándoles para que prosigan con su tarea y propiciando la participación de muchos otros nuevos investigadores.

\section{NOTAS:}

GRUPO INDIANO: este trabajo ha sido realizado por Ana M. ${ }^{\text {a }}$ Fernández Zampaña, Encarnación de la Pascua Sánchez, M. ${ }^{a}$ Isabel Marmolejo López, J. Manuel de la Pascua Sánchez. Isabel Ramírez Rodríguez y M. ${ }^{a}$ de los Ángeles Vicenti Alconchel, integrantes del grupo de investigación "Indiano”, que ha contado para el presente proyecto con subvención de la Universidad de Cádiz (Programa de Grupos Precompetitivos).

GRUPO INTRAHISTORIA: Diego Benítez Mota, Montserrat Forero Fernández, Pilar Gómez Hernández, Antonio J. López Padial, Nieves Macías Delgado, Juan Moreno Nieto y María Dolores Pérez Murillo (Universidad de Cádiz).

GUERRA DE CUBA: así se conoció en España la denominada Guerra de los Diez Años o Guerra Grande (1868-1878). Ésta fue la primera guerra de independencia cubana contra las fuerzas reales españolas. El conflicto comenzó el 10 de octubre de 1868 con el Grito de Yara y finalizó diez años más tarde con la Paz de Zanjón, donde se establece la capitulación del Ejército Independentista Cubano frente a las tropas españolas. Este acuerdo no garantizaba ninguno de los dos objetivos fundamentales que perseguían los insurrectos con dicha guerra: la independencia de Cuba y la abolición de la esclavitud. CHACO: o Gran Chaco es una de las principales regiones geográficas de Sudamérica. Ubicada en el Cono Sur, se extiende por parte de los actuales territorios de la Región del Norte Grande Argentino, Bolivia, Brasil y Paraguay, entre los ríos Paraguay y Paraná y el Altiplano andino.

PODERES: por medio de este tipo documental obtenemos la identidad del emigrante y su destino, y en ocasiones también su vecindad, naturaleza, estado civil... En cuanto a las distintas tipologías de poderes con las que contamos, decir que tenemos poderes para cobrar, para testar, poderes generales (documento que autorizaba una o varias personas la realización de ciertas actividades) etcétera.

TESTAMENTOS: nos informan sobre la naturaleza del testador, su estado civil, fecha y lugar de su matrimonio, nombre del cónyuge, número de hijos, bienes, deudas y motivo por el que testa.

LICENCIAS: en general, las licencias consisten en la concesión de un permiso de una persona a otra para realizar una cierta actividad. Por ejemplo: puede ser un permiso otorgado por un hombre para que su esposa haga un viaje. 
PRORROGACIONES: se conceden para ampliar el tiempo de estancia del emigrado en su lugar de destino. El 100\% de las prorrogaciones fueron otorgadas por mujeres y las licencias lo fueron en un $99 \%$.

PROVISTOS: hacen el viaje a Indias para ocupar un cargo público.

CARGADORES: miembros de la tripulación que, en su mayoría, transportaban un cajón de mercancías.

PASAJEROS: pertenecían a diversas profesiones y grupos sociales.

Para Olavide, los jornaleros eran "los hombres más infelices que yo conozco en Europa... Estos hombres la mitad del año son jornaleros y la otra mitad mendigos”. PABLO DE OLAVIDE: Informe sobre la ley agraria.

En el momento de la redacción del presente artículo, el año 1992, nos cuenta David Fernández que se hallan trabajando en el proyecto de investigación: "Emigración legal a Indias en la época de los Austrias: análisis de las mentalidades a través de las cartas reclamo".

CARTAS-RECLAMO: cartas extraídas de OTTE, Enrique: Cartas privadas de emigrantes a Indias, 1540-1616. Sevilla: Consejería de cultura, Junta de Andalucía, 1988. MARAVALL, J. A.: Poder, honor y élites en el siglo XVII, Madrid, Ed. siglo veintiuno, 1984.

INSTANCIAS: datos que aportan: lugar de origen, edad, estado civil y profesión del emigrante; justificación de que el individuo que desea viajar a Cuba no va a convertirse en un elemento desarraigado allí, pues hay un pariente o amigo ya establecido en la isla que lo reclama y promete colocarlo en su negocio.

"En Santiago de Cuba los catalanes son comerciantes, bodegueros, industriales, y no se les nombra por su oficio o giro, sino que a todo comerciante se le llama catalán, el catalán de la esquina, pues las tiendas estaban en las esquinas”. MARTÍ, Carlos: Los catalanes en América. Barcelona, Editorial Minerva, s. a., 1920.

REAL PATRONATO: o Patronato Regio consistió en el conjunto de privilegios y facultades especiales que los Papas concedieron a los reyes de distintas monarquías europeas del Antiguo Régimen y que les permitían, al principio, ser oídos antes de una decisión Papal o elegir directamente en sustitución de las autoridades eclesiásticas, a determinadas personas que fueran a ocupar cargos vinculados a la Iglesia Católica (Derecho de patronato). 
